Pacific Journal of Mathematics

THE KREĬ N-MILMAN PROPERTY AND COMPLEMENTED

HES IN BANACH PAC 


\title{
THE KREIN-MILMAN PROPERTY AND COMPLEMENTED BUSHES IN BANACH SPACES
}

\author{
AGGIE Ho
}

\begin{abstract}
We give "complementation" as a sufficient condition on a bush in a Banach space for the space to fail the KreinMilman property. We also construct an example of a Banach space $X$ which contains a complemented bush. Hence the space $X$ fails the Krein-Milman property. However the closed convex span of the bush contains infinitely many extreme points and no denting points. Moreover, the closed convex span of these extreme points contains the original bush.
\end{abstract}

1. Introduction. It is an open question whether a nondual Banach space with the Krein-Milman property has the Radon-Nikodým property. Since a Banach space contains a bush if and only if it does not have the Radon-Nikodym property, a space which contains a bush and satisfies the Krein-Milman property would settle this question. Theorem A indicates that such a space must not have a complemented bush. For a summary of results on the Radon-Nikodým property and the Krein-Milman property, see [1, Ch. VII].

A Banach space $X$ is said to have the Krein-Milman property if every bounded closed convex subset in $X$ is the closed convex span of its extreme points. We define a bush in a Banach space $X$ to be a subset

$$
B=\left\{x^{n i}: 1 \leqq i \leqq N(n), n \geqq 1\right\}
$$

of the unit ball of $X$ that satisfies the following conditions:

(B1) For each $n \geqq 1$, the collection of the first $N(n+1)$ positive integers is the union of $N(n)$ consecutive sets

$$
\left\{S_{i}^{n+1}: 1 \leqq i \leqq N(n)\right\}
$$

such that each $S_{i}^{n+1}$ has $r_{i}^{n+1} \geqq 2$ members (the bush is a tree if each $r_{i}^{n}=2$ ) and

$$
x^{n \imath}=\frac{1}{r_{i}^{n+1}} \sum\left\{x_{j}^{n+1}: j \in S_{i}^{n+1}\right\} .
$$

(B2) There is a positive separation constant $\varepsilon$ such that, for each $i$ and every $j \in S_{i}^{n+1}$, the following holds:

$$
\left\|x^{n \imath}-x^{n+1, j}\right\|>\varepsilon .
$$

We say $x^{n+1, j}$ follows $x^{n i}$ or $(n+1, j)>(n, i)$ if $j \in S_{i}^{n+1}$. The 
relation " $>$ " is extended to be transitive. We say

$$
\alpha=\left\{\left(n, i_{n}\right): n \geqq 1\right\}
$$

is a branch if $(n, i)<\left(n+1, i_{n+1}\right)$ for each $n$. A wedge of the bush $B$ is a set of the type:

$$
W_{n \imath}=\left\{x^{m j}:(m, j)>(n, i)\right\} .
$$

A complemented bush is a bush which satisfies the following additional condition:

(B3) There is a positive $\theta$ such that, for each $n$,

$$
\|u-v\| \geqq \theta\|u\|
$$

if $u \in \operatorname{linsp} W_{n i}$ and $v \in \operatorname{linsp}\left\{W_{n k}: k \in S_{j}^{n-1}\right.$ and $\left.k \neq i\right\}$, where each $k$ and $i$ belong to some $S_{j}^{n-1}$.

The concept of approximate bush is useful in constructing new bushes out of old ones and for proving the existence of bushes. We call a set

$$
B_{A}=\left\{x^{n i}: 1 \leqq i \leqq N(n), n \geqq 1\right\}
$$

of the unit ball of $X$ an approximate bush with errors of approximation $\left\{\delta_{n}\right\}$, if each $\delta_{n}>0$ and $\sum \delta_{n}<\infty$, (B2) is satisfied, and for each $n$,

$$
\| x^{n i}-\sum\left\{\frac{x^{n+1, j}}{r_{\imath}^{n+1}}: j \in S_{\imath}^{n+1}\right\} \mid<\delta_{n} .
$$

An approximate complemented bush is an approximate bush that is complemented, that is, (AB1), (B2), and (B3) hold.

The following are some examples of trees and bushes. The trees in Examples 1, 2, 4, and 5 are complemented. The tree in Example 3 is not complemented. The tree in Example 4 is subtree of the uncomplemented tree in Example 3. An approximate bush is described in Example 6. This approximate bush approximates a subbush of the tree in Example 5.

EXAMPLE 1. In the space $L[0,1]$, let $x^{1,1}=1$ on the unit interval $[0,1]$. Inductively, for any $n \geqq 1,1 \leqq i \leqq 2^{n-1}$, define

$$
x^{n i}= \begin{cases}2^{n-1} & \text { on }\left[\frac{i-1}{2^{n-1}}, \frac{i}{2^{n-1}}\right), \\ 0 & \text { otherwise } .\end{cases}
$$

The set $\left\{x^{n}\right\}$ is a complemented tree in the space $L[0,1]$ with complementation constant 1 and separation constant 1 . 
EXAMPLe 2. In the space $C[0,1]$, let $x^{1,1}$ be the linear function on the unit interval $[0,1]$ for which $x^{1,1}(0)=1$ and $x^{1,1}(1)=0$. Inductively, for any $n$ and $i$, if $x^{n i}$ is a linear function on the unit interval $[0,1]$, constant on the intervals $[0, a]$ and $[b, 1]$, and decreasing on the interval $[a, b]$, define

$$
x^{n+1,2 i-1}= \begin{cases}1 & \text { on }\left[0, \frac{a+b}{2}\right], \\ 0 & \text { on }[b, 1], \\ \text { linear } & \text { on }\left[\frac{a+b}{2}, b\right],\end{cases}
$$

and

$$
x^{n+1,2 i}= \begin{cases}1 & \text { on }[0, a], \\ 0 & \text { on }\left[\frac{a+b}{2}, 1\right], \\ \text { linear } & \text { on }\left[a, \frac{a+b}{2}\right] .\end{cases}
$$

The set $\left\{x^{n i}\right\}$ is a complemented tree in the space $C[0,1]$ with complementation constant 1 and separation constant $1 / 2$.

EXAMPLE 3 . In the sequence space $c_{0}$, let $x^{1,1}=(1,0,0, \cdots)$. Inductively, for any $n$ and $i$, if $x^{n i}=\left\{x^{n i}(k)\right\}_{k=1}^{\infty}$, define

$$
x^{n+1,2 i-1}(k)=x^{n+1,2 i}(k)=x^{n i}(k) \text { for } k \neq n+1,
$$

and

$$
x^{n+1,2 i-1}(n+1)=-x^{n+1,2 i}(n+1)=1 .
$$

The set $\left\{x^{n i}\right\}$ is a tree with separation constant 1 . It is not complemented because the element $\left\{2 \delta_{k}^{n+1}\right\}_{k=1}^{\infty}=x^{n+1,2 i-1}-x^{n+1,2 i}=x^{n+1,2 j-1}-$ $x^{n+1,2 j}$ is contained in both linsp $W_{n i}$ and linsp $W_{n j}$.

EXAmple 4. The tree $\left\{x^{n i}\right\}$ in the above example contains many complemented subtrees. In particular, let $y^{1,1}=x^{1,1}, y^{2,1}=x^{2,1}$, and $y^{2,2}=x^{2,2}$. In general, let $y^{n i}=\left\{y^{n i}(k)\right\}_{k=1}^{\infty}$ and define

$$
y^{n+1,2 i-1}\left(2^{n-1}+i\right)=-y^{n+1,2 i}\left(2^{n-1}+i\right)=1,
$$

and

$$
y^{n+1,2 i-1}(k)=y^{n+1,2 i}(k)=y^{n i}(k) \quad \text { for } \quad k \neq 2^{n-1}+i .
$$

Notice that, for $i \neq j$, the elements $y^{n+1,2 i}$ and $y^{n+1,2 j}$ have disjoint support for $k>2^{n-1}$. 
This tree $\left\{y^{n i}\right\}$ is complemented. To see this, let $u \in \operatorname{linsp} W_{n+1,2 i-1}$ and $v \in \operatorname{linsp} W_{n+1,2 i}$. Notice that

$$
u\left(2^{n-1}+i\right)= \pm u\left(2^{n-2}+\left[\frac{i+1}{2}\right]\right)
$$

while

$$
v\left(2^{n-1}+i\right)=\mp v\left(2^{n-2}+\left[\frac{i+1}{2}\right]\right)
$$

where $[s]$ is the greatest integer less than or equal to $s$. We shall show that $\|u-v\| \geqq\|u\|$. If the norm of $u$ is assumed at $k \leqq$ $2^{n-1}+i$, then

$$
\begin{aligned}
\|u-v\| & \geqq \max \left\{|(u-v)(k)|: k=2^{n-1}+i \text { or } k=2^{n-2}+\left[\frac{i+1}{2}\right]\right\} \\
& \geqq\left|u\left(2^{n-1}+i\right)\right| \\
& =\|u\| .
\end{aligned}
$$

On the other hand, if the norm of $u$ is attained at some $k>2^{n-1}+i$, then

$$
\|u-v\| \geqq|u(k)|=\|u\| \text {. }
$$

This is true because $v(k)=0$. Consequently the set $\left\{y^{n i}\right\}$ is a complemented tree with complementation constant 1 . It is easy to see that this tree has separation constant 1.

EXAMPle 5. Let $X$ be the norm-completion of the linear span of the set

$$
T=\left\{x^{n i}: 1 \leqq i \leqq 2^{n-1}, n \geqq 1\right\},
$$

where $x^{n i}$ is a function on a "tree of points" $\left\{(m, j): 1 \leqq j \leqq 2^{m-1}\right.$, $m \geqq 1\}$. Define by

$$
x^{n i}(m, j)= \begin{cases}1 & \text { if }(m, j) \leqq(n, i), \\ 2^{n-m} & \text { if }(m, j)>(n, i), \\ 0 & \text { otherwise },\end{cases}
$$

with a norm defined as follows. Define \|\|$_{2}$ by letting

$$
\|v\|_{2}=\left[\sum_{m, j}[v(m, j)]^{2}\right]^{1 / 2},
$$

if this is finite. Define [[ ]] to have as domain the set of all $u$ for which $u$ has support on one branch. If $u$ has support on the branch $\alpha$, let 


$$
[[v]]=\sum_{n=1}^{\infty}|u(n, i)-u(n+1, j)|,
$$

where each $(n, i)$ and $(n+1, j)$ lie on $\alpha$. Define \|\|$_{1}$ to have as domain the set of all $u$ with finite support. If $u$ has finite support, let

$$
\|u\|_{1}=\inf \left\{\left[\left[u^{k}\right]\right]: u=\sum u^{k}\right\}
$$

where each $u^{k}$ has support on one branch.

If $x \in T$ and $p$ is a positive integer, let $x=u^{p}+v^{p}$, where

$$
u^{p}(m, j)=\left\{\begin{array}{lll}
x(m, j) & \text { if } & m \leqq p \\
0 & \text { if } & m>p
\end{array}\right.
$$

and

$$
v^{p}(m, j)=\left\{\begin{array}{lll}
0 & \text { if } & m \leqq p \\
x(m, j) & \text { if } & m>p
\end{array}\right.
$$

Then define \|\| by letting $\|x\|=\inf \left\{\left\|u^{p}\right\|_{1}+\left\|v^{p}\right\|_{2}: x=u^{p}+v^{p}\right.$ as described above\}.

Remark ( $\mathrm{i}$ ). If $x \in T$, then $\|x\| \leqq 1$. To see this, suppose $x=u^{p}+v^{p}$ as above. Then $\left\|u^{p}\right\|_{1} \leqq 1$. If $p \geqq n$, then

$$
\left\{\left\|v^{p}\right\|_{2}\right\}^{2}=\sum_{m=p}^{\infty} 2^{m-n}\left[2^{n-m}\right]^{2}=2^{1-p+n} \longrightarrow 0 \quad \text { as } \quad p \longrightarrow \infty .
$$

REMARK (ii). $\|x\| \geqq \sup \left\{|x(m, j)|: 1 \leqq j \leqq 2^{m-1}, m \geqq 1\right\}$. To show this, suppose $x=u^{p}+v^{p}$. If $u^{p}=\sum u^{p, k}$, where each $u^{p, k}$ has support on one branch, then

$$
\left[\left[u^{p, k}\right]\right] \geqq \sum_{n=1}^{\infty}\left|u^{p, k}(n, i)-u^{p, k}(n+1, j)\right|,
$$

where each $(n, i)$ and $(n+1, j)$ lie on the branch containing the support of $u^{p, k}$. Therefore

$$
\left[\left[u^{p, k}\right]\right] \geqq\left|u^{p, k}(n, i)\right|,
$$

for all $n$ and $i \leqq 2^{n-1}$. Thus $\left[\left[u^{p, k}\right]\right] \geqq \sup _{n, i}\left\{\left|u^{p, k}(n, i)\right|\right\}$ and

$$
\left\|u^{p}\right\|_{1} \geqq \sup _{n, i}\left\{\left|u^{p}(n, i)\right|\right\} \text {. }
$$

This and $\left\|v^{p}\right\|_{2} \geqq \sup _{n, i}\left\{\left|v^{p}(n, i)\right|\right\}$ imply $\|x\| \geqq \sup _{n, i}\{|x(n, i)|\}$, for all $x$ in $X$.

REMARK (iii). The set $T$ is a tree. From Remarks (i) and (ii), 
we know that $\|x\|=1$ if $x \in T$. Also,

$$
\left\|x^{n+1,2 i-1}-x^{n+1,2 i}\right\| \geqq 1,
$$

if $1 \leqq i \leqq 2^{n-1}$ and $n \geqq 1$. Since the element $x^{n+1,2 i-1}-x^{n+1,2 i}$ has one value of 1 (and one value of -1 .) Consequently, the set $T$ is a tree in the space $X$.

ExAmple 6. Let $\left\{x^{n i}\right\}$ be the tree described in the previous Example. Define a subbush of this tree as follows. Let

$$
\begin{aligned}
& y^{1,1}(m, j)=\left\{\begin{array}{lll}
x^{2^{0,1}}(m, j) & \text { if } & m \leqq 2^{1}, \\
0 & \text { if } & m>2^{1},
\end{array}\right. \\
& y^{2, i}(m, j)=\left\{\begin{array}{lll}
x^{2^{1}, i}(m, j) & \text { if } & m \leqq 2^{2}, \\
0 & \text { if } & m>2^{2},
\end{array}\right.
\end{aligned}
$$

and in general,

$$
y^{n i}(m, j)=\left\{\begin{array}{lll}
x^{2^{n-1}, i}(m, j) & \text { if } & m \leqq 2^{n} \\
0 & \text { if } & m>2^{n}
\end{array}\right.
$$

The set $\left\{y^{n i}: 1 \leqq i \leqq 2^{2^{n-1}-1}, n \geqq 1\right\}$ is an approximate bush with errors in approximation $\left\{2^{-2^{n-1}}: n \geqq 1\right\}$.

2. Bushes and approximate bushes. We show that if a Banach space contains an approximate bush then it contains a bush. Moreover, the approximate bush is asymptotically close to the bush.

LEMMA 1. If a Banach space $X$ contains an approximate bush, then this bush contains a subbush $B_{A}=\left\{x^{n i}\right\}$ for which there is a bush $B=\left\{y^{n i}\right\}$ such that, if $y^{n i} \in B$, then

$$
\lim _{n \rightarrow \infty} \sup \left\{\left\|y^{n i}-x^{n i}\right\|: i \in N(n+1)\right\}=0 .
$$

Moreover, if $B_{A}$ is complemented, then so is $B$.

Proof. First choose a subbush for which the errors $\left\{\delta_{n}\right\}$ in approximation satisfy $\sum \delta_{n}<\varepsilon / 3$, where $\varepsilon$ is the separation constant for the approximate bush. Given $x^{n i}$, we define $x_{p}^{n i}$ as a weighted average of those followers of $x^{n i}$ that can be joined to $x^{n i}$ by a chain of $p$ successive members of the approximate bush $\mathrm{B}_{A}$, where the weights are chosen in the obvious natural way. Very analogously with the proof of Lemma 1 in [2], it follows that if

$$
y^{n i}=\lim _{p \rightarrow \infty} x_{p}^{n i}
$$


for each $(n, i)$, then $\left\{y^{n i}\right\}$ is a bush for which $\varepsilon / 3$ is a separation constant. Condition (1) is satisfied, because the following holds:

$$
\left\|y^{n i}-x^{n i}\right\|<\sum_{n}^{\infty} \delta_{k} \longrightarrow 0 \quad \text { as } n \longrightarrow 0 \text {. }
$$

To see that $B$ is complemented if $B_{A}$ is complemented, let $(n, i)$ be arbitrary and choose $\theta>0$ so that $\|u-v\| \geqq \theta\|u\|$ if $u \epsilon$ linsp $W_{n i}\left(B_{A}\right)$ and $v \in \operatorname{linsp}\left\{W_{n k}\left(B_{A}\right): k \neq i\right\}$, where $k$ and $i$ belong to some $S_{j}^{n-1}$. Suppose $\bar{u}=\sum a_{r} \bar{u}_{r}$ with each $\bar{u}_{r} \in W_{n i}(B)$, and $\bar{v}=\sum b_{s} \bar{v}_{s}$ with each $\bar{v}_{s}$ belonging to some $W_{n k}(B)$ with $k \neq i$. Then each $\bar{u}_{i}$ can be represented as a convex combination of elements arbitrarily far out the wedge $W_{n i}(B)$, so that $\bar{u}$ is nearly equal to a member of the linear span of $W_{n i}\left(B_{A}\right)$. Since a similar statement can be made for $\bar{v}$, it follows that

$$
\|\bar{u}-\bar{v}\| \geqq \theta\|\bar{u}\|
$$

\section{The Krein-Milman property and complemented bushes.}

Lemma 2. Let $x$ be an extreme point of the closed convex span of a complemented bush in a Banach space. Then there is a branch $\alpha$ for which $x$ belongs to the intersection of closed convex span of wedges along the branch $\alpha$; i.e.,

$$
x \in \cap\left\{\overline{\operatorname{co}} W_{n i}:(n, i) \in \alpha\right\},
$$

Proof. Suppose that, for some $n$ and $i, x$ is an element in the set

$$
\left(\overline{\mathrm{co}}\left[\overline{\mathrm{co}} W_{n i}, \overline{\mathrm{co}}\left\{\overline{\mathrm{co}} W_{n k}: k \neq i\right\}\right]\right) \backslash\left(\operatorname{co}\left[\overline{\mathrm{co}} W_{n i}, \overline{\mathrm{co}}\left\{\overline{\mathrm{co}} W_{n k}: k \neq i\right\}\right]\right)
$$

where $k$ and $i$ belong to some $S_{j}^{n-1}$. Then, by passing to a subsequence, there is a positive number $\lambda<1$, and there are sequences $\left\{y_{p}\right\}$ and $\left\{z_{p}\right\}$ contained in $\overline{c_{0}} W_{n i}$ and $\overline{\mathrm{co}}\left\{\overline{\mathrm{co}} W_{n k}: k \neq i\right\}$ respectively such that

$$
\lambda y_{p}+(1-\lambda) z_{p} \longrightarrow x .
$$

Consequently $\lambda\left(y_{p}-y_{q}\right)+(1-\lambda)\left(z_{p}-z_{q}\right) \rightarrow 0$ as $p$ and $q$ approach $\infty$. Since the bush is complemented, the sequences $\left\{y_{p}\right\}$ and $\left\{z_{p}\right\}$ are Cauchy. Let $y=\lim _{p \rightarrow \infty} y_{p}$ in $\overline{\operatorname{co}} W_{n i}$ and $z=\lim _{p \rightarrow \infty} z_{p}$ in $\overline{\operatorname{co}}\left\{\overline{\operatorname{co}} W_{n k}\right.$ : $k \neq i\}$. Then

$$
x=\lambda y+(1-\lambda) z, \quad \text { for } 0<\lambda<1 .
$$

Thus, for some $n$ and $S_{j}^{n-1}$, and for some $i$ and each $k$ belonging to $S_{j}^{n-1}$, if $x$ is an extreme point for $\overline{\mathrm{co}}\left[\overline{\mathrm{co}} W_{n i}, \overline{\mathrm{co}}\left\{\overline{\mathrm{co}} W_{n k}: k \neq i\right\}\right]$, then 
it must belong to either $\overline{\mathrm{co}} W_{n i}$, or $\overline{\mathrm{co}}\left\{\overline{\mathrm{co}} W_{n k}: k \neq i\right\}$. By repeating this process, we have that, if $x$ is an extreme point for the closed convex span of a complemented bush in a Banach space, then there is a branch $\alpha$ for which $x$ belongs to the intersection of the closed convex span of wedges along the branch $\alpha$.

LEMMA 3. If $B$ is a complemented bush, then there are at most countably many branches $\alpha$ for which $\cap\left\{\overline{\mathrm{co}} W_{n}:(n, i) \in \alpha\right\}$ contains a nonzero element.

Proof. For an arbitrary $\delta>0$, choose for each branch $\alpha$ a member $x^{\alpha}$ of $\cap\left\{\overline{\operatorname{co}} W_{n i}:(n, i) \in \alpha\right\}$ with $\left\|x^{\alpha}\right\|>\delta$, if such an $x^{\alpha}$ exists. If $x^{\alpha}$ and $x^{\beta}$ are such elements for different branches $\alpha$ and $\beta$, then

$$
\left\|x^{\alpha}-x^{\beta}\right\| \geqq \theta \delta,
$$

where $\theta$ is the complementation constant. Since the closed linear span of $B$ is separable, there can be at most countably many such $x^{\alpha}$ 's with norm at least $\delta$. Thus there are at most countably many branches $\alpha$ for which $\cap\left\{\overline{\mathrm{co}} W_{n i}:(n, i) \in \alpha\right\}$ contains a nonzero member.

Lemma 4. If a Banach space $X$ contains a complemented bush, then it contains a complemented bush whose closed convex span contains at most one extreme point.

Proof. Let $B$ be a complemented bush with complementation constant $\theta$. By Lemma 3 , there can be at most countably many branches $\alpha$ for which $\cap\left\{\overline{c o} W_{n i}:(n, i) \in \alpha\right\}$ contains a nonzero element. Order these branches: $\alpha_{1}, \alpha_{2}, \cdots$. For each $k$ let $p(k)=2^{k+1}$. For each $k$, remove all members of $B$ that belong to $W_{p(k+1), i}$, where $(p(k+1), i) \in \alpha_{k}$. It is not difficult to see that the remaining members of $B$ form an approximate bush with errors in approximation $\left\{2^{-k}: k=1,2, \cdots\right\}$. Now we can obtain, by using the method of proving Lemma 1, a bush that is complemented and for which $\cap\left\{\right.$ co $\left.W_{n i}:(n, i) \in \alpha\right\}$ contains no nonzero element. It follows from Lemma 2 that the closed convex span of the bush has at most one extreme point.

THEOREM A. If a Banach space has a complemented bush, then it fails the Krein-Milman property.

4. An example. We construct a norm on a linear space of functions on the set of ordered pairs $S=\left\{(n, i): 1 \leqq i \leqq 2^{n-1}, n \geqq 1\right\}$. We show that this space contains a complemented bush (actually a complemented tree) whose closed convex span contains infinitely many 
extreme points and no denting points. Moreover, the closed convex span of these extreme points contains the original bush.

Since a tree is a bush for which each member has two successors, we can represent a tree as

$$
T=\left\{x^{n i}: 1 \leqq i \leqq 2^{n-1}, n \geqq 1\right\},
$$

where the two successors of $x^{n i}$ are $x^{n+1,2 i-1}$ and $x^{n+1,2 i}$. We say a branch $\alpha=\left\{\left(n, i_{n}\right): n=1,2, \cdots\right\}$ turns left at $k$ if $i_{k+1}=2 i_{k}-1$. We say a branch is left-turning after $k$ if it turns left at $n$ for all $n \geqq k$, but not for $n=k-1$. We say a branch turns right at $n=k$ if it does not turn left at $n=k$.

Let us know define a particular tree $T=\left\{x^{n i}\right\}$, in the following manner. The function $x^{1,1}$ is identically zero, and the other functions are defined inductively so that:

$$
\begin{aligned}
& x^{n+1,2 i-1}(m, j)=x^{n+1,2 i}(m, j)=x^{n i}(m, j) \quad \text { if } \quad(m, j) \neq(n, i), \\
& x^{n+1,2 i-1}(n, i)=1, \quad x^{n+1,2 i}(n, i)=-1 .
\end{aligned}
$$

We note that the averaging property (B1) holds for these elements. Before defining a norm on $T$, we construct positively homogeneous functions $B_{\alpha}(\cdot)$ with domains all functions on $S$ with finite support. We do this for each branch $\alpha$ that is left-turning after $k$ for some $k$ :

$$
\begin{aligned}
B_{\alpha}(x)= & \sqrt{\frac{1}{2}}\left\{\left[|x(1)|+\sum_{j=1}^{k-1}|\alpha(j+1) x(j+1)-\alpha(j) x(j)|\right]^{2}\right. \\
& \left.+\sum_{j=k}|x(j+1)-x(j)|^{2}+\sum_{(m, j) \in \alpha}|x(m, j)|^{2}\right\}^{1 / 2},
\end{aligned}
$$

where $x(j)=x\left(j, i_{j}\right)$ for $\left(j, i_{j}\right) \in \alpha$, and $\alpha(j)=(-1)^{i_{j+1}-1}$, that is, $\alpha(j)$ is +1 if $\alpha$ turns left at $j$ and it is -1 if $\alpha$ turns right at $j$.

Definition. The function $\|\cdot\|$ is defined on the linear span of $T$ by letting

$$
\|x\|=\inf \left\{\sum B_{\alpha(j)}\left(x^{j}\right): x=\sum_{j=1}^{m} x^{j}\right\},
$$

where the infimum is taken over all finite decompositions $\left\{x^{j}\right\}$ of $x$ and all choices of the branch $\alpha(j)$ for each $j$.

For any $y$ and $z$ in the linear span of $T$, there are finite decompositions $\left\{y^{j}\right\}$ and $\left\{z^{j}\right\}$ and choices of branches such that

$$
\begin{aligned}
\|y\|+\|z\| & \cong \sum B_{\alpha(j)}\left(y^{j}\right)+\sum B_{\beta(j)}\left(z^{j}\right) \\
& \geqq\|y+z\| .
\end{aligned}
$$

Therefore $\|\cdot\|$ is, in fact, a norm on the linear span of $T$. 
Definition. We define the Banach space $X$ to be the $\|\cdot\|$-completion of the linear span of $T$. It is clear that $X$ is in fact a space of functions on $S$ with norm as defined above.

Lemma 5. In the Banach space $X$, the following inequalities hold for each element $x$ in $X$ :

(5a) $\|x\| \geqq 1 / 4|x(n, i)-x(n+1,2 i-1)|$,

(5b) $\|x\| \geqq 1 / 2|x(n, i)|$ if $i$ is even,

(5c) $\quad\|x\| \geqq 1 / 6|x(n, i)-x(n+1,2 i-1)-x(n+1,2 i)|$,

(5d) $\quad\|x\| \geqq \sqrt{1 / 2}|x(1,1)|$.

Proof. We can get (5c) by using a weighted average of (5a) and $(5 \mathrm{~b})$, with $(n+1,2 i)$ in place of $(n, i)$ in $(5 \mathrm{~b}) ;(5 \mathrm{~d})$ is immediate from the definition. It remains to prove (5a) and (5b). Let $x$ be an element in $X$. Fix $(n, i)$ and consider $B_{\alpha}(x)$ where $\alpha$ is left-turning after $k$. We continue to use the notation $x(j)=x\left(j, i_{j}\right)$ if $\left(j, i_{j}\right) \in \alpha$, and $\alpha(j)$ is +1 or -1 according as $\alpha$ turns left or right at $j$.

Case A. If the branch $\alpha$ passes through $(n, i)$ and $k>n$, then

$$
\begin{aligned}
B_{\alpha}(x)= & \sqrt{\frac{1}{2}}\left\{\left[|x(1)|+\sum_{j=1}^{k-1}|\alpha(j+1) x(j+1)-\alpha(j) x(j)|\right]^{2}\right. \\
& \left.+\sum_{j=k}^{\infty}|x(j+1)-x(j)|^{2}+\sum_{(m, j) \notin \alpha}|x(m, j)|^{2}\right\}^{1 / 2} \\
\geqq & \frac{1}{2}\{[|\alpha(1) x(1)|+\cdots+|\alpha(n-1) x(n-1)-\alpha(n) x(n)| \\
& +|\alpha(n) x(n)-\alpha(n+1) x(n+1)| \\
& \left.\left.+\sum_{n+1}^{k-1}|\alpha(j+1) x(j+1)-\alpha(j) x(j)|\right]^{2}+u^{2}\right\}^{1 / 2},
\end{aligned}
$$

where $u^{2}=\sum_{j=k}^{\infty}|x(j+1)-x(j)|^{2}+\sum_{(m, j) \neq \alpha}|x(m, j)|^{2}$. Thus

$$
B_{\alpha}(x) \geqq \frac{1}{2}\left\{[|x(n)|+|\alpha(n) x(n)-\alpha(n+1) x(n+1)|]^{2}+u^{2}\right\}^{1 / 2} .
$$

Hence

$$
B_{\alpha}(x) \geqq \frac{1}{2}|x(n)|=\frac{1}{2}|x(n, i)| .
$$

Also, $\quad B_{\alpha}(x) \geqq 1 / 2|x(n+1)|$, and $\quad B_{\alpha}(x) \geqq 1 / 2 u \geqq 1 / 2|x(n+1, j)|$, if $(n+1, j) \notin \alpha$. So we have,

$$
B_{\alpha}(x) \geqq \frac{1}{4}(|x(n, i)|+|x(n+1,2 i-1)|) .
$$

Case B. If the branch $\alpha$ passes through $(n, i)$ and $k=n$, then 
$B_{\alpha}(x) \geqq(1 / 2)|x(n, i)|$, as in (2) of Case $\mathrm{A}$, and

$$
\begin{aligned}
B_{\alpha}(x) & \geqq \sqrt{\frac{1}{2}}|x(n)-x(n+1)| \\
& =\sqrt{\frac{1}{2}}|x(n, i)-x(n+1,2 i-1)| .
\end{aligned}
$$

Case C. If the branch $\alpha$ passes through $(n, i)$ and $k<n$, then $i$ is odd, and

$$
\begin{aligned}
B_{\alpha}(x)= & \sqrt{\frac{1}{2}}\left\{\left[|x(1)|+\left[\sum_{j=1}^{k-1}|\alpha(j+1) x(j+1)-\alpha(j) x(j)|\right]^{2}\right.\right. \\
& +|x(n)-x(n+1)|^{2} \\
& \left.+\sum_{j=k, j \neq n}^{\infty}|x(j+1)-x(j)|^{2}+\sum_{(m, j) \notin \alpha}|x(m, j)|^{2}\right\}^{1 / 2} \\
\geqq & \sqrt{\frac{1}{2}}|x(n)-x(n+1)| \\
\geqq & \sqrt{\frac{1}{2}}|x(n, i)-x(n+1,2 i-1)| .
\end{aligned}
$$

Case D. If the branch $\alpha$ does not pass through $(n, i)$, then

$$
B_{\alpha}(x) \geqq \frac{1}{2}\{|x(n, i)|+|x(n+1,2 i-1)|\},
$$

and

$$
B_{\alpha}(x) \geqq \sqrt{\frac{1}{2}}|x(n, i)| .
$$

Since $(5 \mathrm{a})$ and $(5 \mathrm{~b})$ are satisfied with $\|\cdot\|$ replaced by $B_{\alpha}(\cdot)$, it now follows easily from the definition of $\|\cdot\|$ that (5a) and (5b) are satisfied as stated.

Lemma 6. The set $T$ is a complemented tree in the space $X$.

Proof. We shall show that the tree is a complemented tree with separation constant $1 / 6$, and complementation constant $1 / 7$.

To obtain the separation constant, we observe that $\left|\left(x^{n i}-x^{n+1, j}\right)(n, i)\right|=1$ if $j$ is either $2 i-1$ or $2 i$. So it follows from both $x^{n i}$ and $x^{n+1, j}$ being 0 at $(n+1,2 i-1)$ and $(n+1,2 i)$, and from (5c), that the separation constant is $1 / 6$.

Finally, we show that the complementation constant is $1 / 7$. To see this, let $y \in \operatorname{linsp} W_{n+1,2 i-1}$ and let $z \in \operatorname{linsp} W_{n+1,2 i}$. It is clear that there is a number $a$ such that, if $\alpha$ is a branch through $(n, i)$, $m<n$, and $(m, j) \in \alpha$, then 


$$
y(m, j)=\alpha(m) a .
$$

Similarly, there is a number $b$, such that, for $m<n$ and $(m, j) \in \alpha$,

$$
z(m, j)=\alpha(m) b .
$$

Thus, $y(1,1)+z(1,1)=\alpha(1)(a+b)$, and if $\left(n-1, i_{n-1}\right) \in \alpha$, then

$$
y\left(m-1, i_{n-1}\right)+z\left(n-1, i_{n-1}\right)=\alpha(n-1)(a+b) .
$$

Also, $y(n, i)+z(n, i)=(a-b)$, and $y(n, k)+z(n, k)=0$, if $k \neq i$. From (5c) we have

$$
\begin{aligned}
\|y+z\| & \geqq \frac{1}{6}\left|(y+z)\left(n-1, i_{n-1}\right)-(y+z)(n, i)-(y+z)(n, k)\right| \\
& \geqq \begin{cases}\frac{1}{3}|b| \text { if } i \text { is odd }, \\
\frac{1}{3}|a| \text { if } i \text { is even . }\end{cases}
\end{aligned}
$$

It follows from (5d) that

$$
\|y+z\| \geqq \sqrt{\frac{1}{2}}|y(1,1)+z(1,1)| \geqq \sqrt{\frac{1}{2}}|a+b| \geqq \frac{1}{2}|a+b| .
$$

If $i$ is even, then $\|y+z\| \geqq 2 / 5(3 / 2 \cdot 1 / 3|a|+1 \cdot 1 / 2|a+b|) \geqq 1 / 5|b|$. Thus for $i$ odd or even,

$$
\|y+z\| \geqq \frac{1}{5}|b| .
$$

We proceed to show that

$$
\|y+z\| \geqq \frac{1}{6}\|z\| \text { and }\|y+z\| \geqq \frac{1}{7}\|y\|,
$$

that is $1 / 7$ is a complementation constant. To estimate $\|y+z\|$, we assume that $\left\{x^{p}\right\}_{p=1}^{r}$, associated with branches $\alpha_{p}$, gives

$$
\|y+z\| \cong \sum B_{p}\left(x^{p}\right) \text {. }
$$

Define $\bar{z}$ by letting $\bar{z}(m, j)=z(m, j)=\alpha(m) b$ if $(m, j)<(n, i), \bar{z}(n, i)=$ $-b$, and $\bar{z}(m, j)=0$ otherwise. Then

$$
\|\bar{z}\| \leqq B(\bar{z}) \leqq \sqrt{\frac{1}{2}}\left\{|b|^{2}+|b|^{2}\right\}^{1 / 2}=|b| .
$$

From (6) and (7), we have

$$
\|y+z\| \geqq \frac{1}{5}|b| \geqq \frac{1}{5}\|\bar{z}\| .
$$


Now let $A=\left\{x^{p}\right.$ : the branch $\alpha_{p}$ does not pass through $\left.(n+1,2 i)\right\}$. $B=\left\{x^{p}\right.$ : the branch $\alpha_{p}$ does pass through $\left.(n+1,2 i)\right\}$.

Case A. If $x^{p} \in A$, define $x_{A}^{p}$ by letting

$$
x_{A}^{p}= \begin{cases}x^{p}(m, j) & \text { if }(m, j) \geqq(n+1,2 i), \\ 0 & \text { otherwise } .\end{cases}
$$

Then $B_{p}\left(x^{p}\right) \geqq \sqrt{1 / 2}\left\{\sum\left|x^{p}(m, j)\right|^{2}:(m, j) \notin \alpha_{p}\right\}^{1 / 2}$

$$
\geqq\left\|x_{A}^{p}\right\| \text {. }
$$

Case B. If $x^{p} \in B$, define $x_{B}^{p}$ by letting

$$
x_{B}^{p}= \begin{cases}x^{p}(m, j) & \text { if }(m, j) \geqq(n+1,2 i), \\ 0 & \text { otherwise } .\end{cases}
$$

Since $\alpha_{p}$ turns right at $(n, i)$, there is a $k>n$ for which we have

$$
\begin{aligned}
B_{p}\left(x^{p}\right) \geqq & \sqrt{\frac{1}{2}}\left\{\left[\left|x^{p}(1)\right|+\sum_{j=1}^{k-1}\left|\alpha(j+1) x^{p}(j+1)-\alpha(j) x^{p}(j)\right|\right]^{2}\right. \\
& \left.+\sum_{j=k}^{\infty}\left|x^{p}(j+1)-x^{p}(j)\right|^{2}+\sum_{(m, j) \notin \alpha}\left|x^{p}(m, j)\right|^{2}\right\}^{1 / 2} \\
\geqq & \sqrt{\frac{1}{2}}\left\{\left|x_{B}^{p}(n+1)\right|^{2}+\left[\sum_{j=n+1}^{k-1}\left|\alpha(j+1) x_{B}^{p}(j+1)-\alpha(j) x_{B}^{p}(j)\right|\right]^{2}\right. \\
& \left.+\sum_{j=k}^{\infty}\left|x_{B}^{p}(j+1)-x_{B}^{p}(j)\right|^{2}+\sum_{(m, j) \notin \alpha}\left|x_{B}^{p}(m, j)\right|^{2}\right\}^{1 / 2} \\
\geqq & \left\|x_{B}^{p}\right\| .
\end{aligned}
$$

Combining (9) and (10), we have,

$$
\|y+z\| \geqq \sum_{A}\left\|x_{A}^{p}\right\|+\sum_{B}\left\|x_{B}^{p}\right\| .
$$

Averaging (8) and (11) with weights $5 / 6$ and $1 / 6$, we get

$$
\|y+z\| \geqq \frac{1}{6}\left\{\sum_{A}\left\|x_{A}^{p}\right\|+\sum_{B}\left\|x_{B}^{p}\right\|+\|\bar{z}\|\right\} .
$$

Since $\sum_{A} x_{A}^{p}+\sum_{B} x_{B}^{p}+\bar{z}=z$, we have

$$
\|y+z\| \geqq \frac{1}{6}\|z\| \text {. }
$$

Also, since $\|y\| \leqq\|y+z\|+\|z\| \leqq 7\|y+z\|$, we have finally,

$$
\|y+z\| \geqq \frac{1}{7}\|y\| \text {. }
$$


Thus the complementation constant is at least $1 / 7$.

This concludes Lemma 6 . We see from this lemma and Theorem A that the space $X$ does not have the Krein-Milman property. We proceed to prove the following theorem.

THEOREM B. There is a Banach space which contains a tree for which the closed convex span of this tree contains infinitely many extreme points, but no denting points. Moreover, the closed convex span of these extreme points contains the original tree.

Proof. Let $X$ be the Banach space and $T$ be the tree constructed above. We show first that, for a branch $\alpha$ that is left-turning after some point, the element $x^{\alpha}$ defined by

$$
x^{\alpha}(m, j)= \begin{cases}\alpha(m) & \text { if }(m, j) \in \alpha, \\ 0 & \text { otherwise },\end{cases}
$$

belongs to the closed convex span of $T$. Next, we shall show that each $x$ is an extreme point, but not a denting point. Then, we shall show that the closed convex span of $T$ has no other extreme points. Finally, we shall show that the closed convex span of these extreme points contains $T$.

Let $\alpha$ be a branch that is left-turning after $k$. For every $\left(n, i_{n}\right) \in \alpha$, let $x^{n}$ denote $x^{n, i_{n}}$. For each $n>k, x^{n}\left(m, i_{m}\right)=1$, if $k \leqq m<n$. For some $s \geqq k$ and some positive integer $p$, let

$$
y_{s}^{p}=\sum_{n=s+1}^{s+p} \frac{1}{p} x^{n}
$$

If $t>s+p$ and $q$ is a positive integer, then

$$
\left(y_{t}^{q}-y_{s}^{p}\right)(m, j)= \begin{cases}i / p & \text { if }(m, j) \in \alpha \text { and } s \leqq m=s+i<s+p \\ 1 & \text { if }(m, j) \in \alpha \text { and } s+p \leqq m \leqq t \\ 1-i / q & \text { if }(m, j) \in \alpha \text { and } t \leqq m=t+i \leqq t+q \\ 0 & \text { otherwise }\end{cases}
$$

Thus if $B\left(y_{s}^{p}-y_{t}^{q}\right)$ is associated with the branch $\alpha$, then

$$
\begin{aligned}
\left\|y_{s}^{p}-y_{t}^{q}\right\| & \leqq B\left(y_{s}^{p}-y_{t}^{q}\right) \\
& =\sqrt{\frac{1}{2}}\left\{(p+1) / p^{2}+(q+1) / q^{2}\right\}^{1 / 2} \\
& \longrightarrow 0, \quad \text { as } p, q, s, t \longrightarrow \infty .
\end{aligned}
$$

Therefore $\left\{y_{s}^{p}\right\}$ converges to an element $x^{\alpha}$ in $X$. Furthermore, it belongs to the closed convex span of $T$. We notice that, from (5c), 


$$
\begin{aligned}
\left\|x^{\alpha}-x^{n}\right\| & \geqq \frac{1}{6}\left\|\left(x^{\alpha}-x^{n}\right)\left(n-1, i_{n-1}\right)-\left(x^{\alpha}-x^{n}\right)(n, i)-\left(x^{\alpha}-x^{n}\right)(n, k)\right\| \\
& =\frac{1}{6},
\end{aligned}
$$

where both $(n, i)$ and $(n, k)$ follow $\left(n-1, i_{n-1}\right)$. Thus the element $x^{\alpha}$ is not a denting point for the closed convex span of $T$.

To show that each $x^{\alpha}$ is an extreme point for the closed convex span of $T$, assume that $x^{\alpha}=(1 / 2)(y+z)$ for some $y, z$ in $\overline{c o}(T)$. Clearly, for each $(n, i) \in \alpha, y(n, i)=z(n, i)=x(n, i)=\alpha(n)= \pm 1$. Given $\delta>0$, let $(m, j) \notin \alpha$. Assume $(m, j)$ lies on a branch $\beta$ such that $\alpha$ and $\beta$ split at $(k, h)$. That is $\alpha \cap \beta=\{(n, i) \in \alpha: n \leqq k\}$. Since point evaluation maps are continuous (though not uniformly bounded for odd $i$ 's), for $(m, j)$ and $(k, h)$ fixed, there is a finite subset $\left\{x^{i}: 1 \leqq i \leqq p\right\}$ of $T$ and corresponding convex coefficients $\left\{\lambda_{i}>0\right.$ : $\left.\sum_{i=1}^{p} \lambda_{1}=1\right\}$ such that

$$
\left|y(m, j)-\sum \lambda_{i} x^{i}(m, j)\right|<\frac{1}{2} \delta,
$$

and

$$
\left|y(k, h)-\sum \lambda_{\imath} x^{i}(k, h)\right|<\frac{1}{2} \delta .
$$

Let $\lambda=\sum\left\{\lambda_{i}: x^{i}(m, j)=1\right\}$, and $\mu=\sum\left\{\lambda_{i}: x^{i}(m, j)=-1\right\}$. Then

$$
|\lambda[y(m, j)-1]+\mu[y(m, j)+1]+[1-\lambda-\mu] y(m, j)|<\frac{1}{2} \delta,
$$

and

$$
|y(m, j)-\lambda+\mu|<\frac{1}{2} \delta .
$$

Let $\lambda=\sum\left\{\lambda_{i}: x^{i}(k, h)=\beta(k)=-\alpha(k)\right.$, i.e., $x^{i}$ splits off from $\alpha$ at $(k, h)\}$. Then, since $m>k$,

$$
\nu \geqq \lambda+\mu \text {. }
$$

Let $\omega=\sum\left\{\lambda_{i}: x^{i}(k, h)=0\right\}$. Now at $(k, h)$,

$$
\begin{aligned}
\left|\sum \lambda_{i} x^{i}(k, h)-y(k, h)\right|= & \mid \nu[\beta(k)-\alpha(k)]+\omega[0-\alpha(k)] \\
& +[1-\nu-\omega][\alpha(k)-\alpha(k)] \mid<\frac{1}{2} \delta .
\end{aligned}
$$

Since $\beta(k)=-\alpha(k)$,

$$
|-2 \alpha(k) \nu-\alpha(k) \omega|<\frac{1}{2} \delta,
$$


or

$$
\nu+\frac{1}{2} \omega<\frac{1}{4} \delta
$$

From (13) and the above, we have $\lambda+\mu \leqq \nu<(1 / 4) \delta$. Combining this with (12), we have,

$$
|y(m, j)| \leqq \frac{1}{2} \delta+\lambda+\mu<\frac{3}{4} \delta<\delta
$$

Since $\delta$ is arbitrary, $y(m, j)=0$ for $(m, j) \notin \alpha$. Thus $x^{\alpha}=y=z$ is an extreme point.

Next, we show that the set $\overline{\text { co }}(T)$ contains no other extreme points. Consequently it cannot have any denting points.

We see from Theorem A that, if $x$ is an extreme point for $\overline{\operatorname{co}}(T)$, then there must be a branch $\beta$ such that $x \in \cap\left\{\overline{c o} W_{n i}:(n, i) \in \beta\right\}$. If $\beta$ is a branch that is left-turning after some point, then, from the continuity of point evaluation, $x=x^{\beta}$. We shall show that, if $\beta$ is not left-turning after any point, then the intersection of wedges $\cap\left\{\overline{c o} W_{n i}:(n, i) \in \beta\right\}$ is void. Assume the opposite, so there is an $\bar{x} \in$ $\cap\left\{\overline{\mathrm{co}} W_{n i}:(n, i) \in \beta\right\}$. Then, by the continuity of the point-evaluation map, $\bar{x}(m, j)=\beta(m)$, for $(m, j) \in \beta$. Claim, the element $\bar{x}$ cannot belong to $X$. Since, for every $x$ in $T$ there is a positive integer $N$ such that $x(n, i)=0$ for $n>N$, and since $\beta$ turns right infinitely often, there is a point $(m, j)$ in $\beta$, with $m>N$ and $j$ even, such that (5b) applies. Specifically,

$$
\|\bar{x}-x\| \geqq \sqrt{\frac{1}{2}}|\bar{x}(m, j)-x(m, j)|=\sqrt{\frac{1}{2}}|\beta(m)-0|=\sqrt{\frac{1}{2}} .
$$

Thus $\bar{x} \notin \overline{\text { co }}(T)$. Therefore the closed convex span of $T$ contains no denting points.

Finally, we show that the closed convex span of these extreme points $\left\{x^{\alpha}\right\}$ contains the original tree $T$.

First, we show that $x^{1,1} \in \overline{\mathrm{co}}\left\{x^{\alpha}: \alpha\right.$ is a branch that turns left after some point\}. Given $\delta>0$. Choose a descending sequence of positive numbers $\left\{\theta_{k}\right\}_{k=1}^{\infty}$ which satisfies the following:

$$
\sum_{k} \theta_{k}^{2}<\infty \text { and }\left\{\sum_{k=1}^{\infty}\left(\theta_{k+1}-\theta_{k}\right)^{2}\right\}^{1 / 2}<\sqrt{\frac{1}{2}} \delta
$$

Choose $p$ so that $\left\{2^{-p} \sum \theta_{k}^{2}\right\}^{1 / 2}<\sqrt{1 / 2} \delta$. Let $\alpha_{q}$ be the branch through $(p+1, q)$ which turns left for all $m \geqq p$. Let $x_{q}$ be defined as follows:

and

$$
\begin{cases}x_{q}(p+k, j)=\theta_{k} & \text { if } k \geqq 1 \text { and }(p+k, j) \in \alpha_{q}, \\ x_{q}(m, j)=x^{\alpha_{q}}(m, j) & \text { otherwise . }\end{cases}
$$


We note that

$$
\left\|x^{\alpha_{q}}-x_{q}\right\| \leqq B_{n_{q}}\left(x^{\alpha_{q}}-x_{q}\right)=\sqrt{\frac{1}{2}}\left\{\sum\left(\theta_{k+1}-\theta_{k}\right)^{2}\right\}^{1 / 2}<\frac{1}{2} \delta .
$$

Also

$$
\begin{aligned}
\left\|2^{-p} \sum x_{q}-x^{1,1}\right\| & \leqq B_{\alpha_{q}}\left(2^{-p} \sum x_{q}-x^{1,1}\right) \\
& \leqq \sqrt{\frac{1}{2}}\left\{\sum 2^{p}\left(\frac{\theta_{k}}{2^{p}}\right)^{2}\right\}^{1 / 2} \leqq \frac{1}{2} \delta .
\end{aligned}
$$

Combining (14) and (15), we have

$$
\begin{aligned}
\left\|2^{-p} \sum x^{\alpha_{q}}-x^{1,1}\right\| & \leqq\left\|2^{-p} \sum\left(x^{\alpha_{q}}-x_{q}\right)\right\|+\left\|2^{-p} \sum x_{q}-x^{1,1}\right\| \\
& <\delta .
\end{aligned}
$$

Since $\delta$ is arbitrary, $x^{1,1} \in \overline{\mathrm{co}}\left\{x^{\alpha}\right\}$. It is not difficult to see that the tree $T$ is contained in the closed convex span of the extreme points $\left\{x^{n}\right\}$.

REMARK. This example is essentially the example in 13, pp. $60-73]$.

\section{REFERENCES}

1. J. Diestel and J. J. Uhl, Vector measures, Math Surveys, 15 (1977), Amer. Math. Soc.

2. A. Ho, The Radon-Nikodym property and weighted trees in Banach spaces, Israel J. Math., Vol. 32, No. 1, (1979), 59-66.

3. - Trees, tree-like structures, and extreme points in Banach spaces, Ph. D. Thesis. Claremont Graduate School, 1978.

Received September 3, 1980 and in revised form December 12, 1980.

Iowa State University

AMES, IA 50011 



\title{
PACIFIC JOURNAL OF MATHEMATICS
}

\section{EDITORS}

\author{
DONALD BABBITT (Managing Editor) \\ University of California \\ Los Angeles, CA 90024 \\ Hugo RossI \\ University of Utah \\ Salt Lake City, UT 84112 \\ C. C. MOORE and ANDREW OGG \\ University of California \\ Berkeley, CA 94720
}

J. DugundjI

Department of Mathematics

University of Southern California

Los Angeles, CA 90007

R. FinN and J. Milgram

Stanford University

Stanford, CA 94305

\section{ASSOCIATE EDITORS}
R. ARENS
E. F. Beckenbach
B. H. NeumanN
F. WOLF
K. YoSHIDA

\section{SUPPORTING INSTITUTIONS}

\author{
UNIVERSITY OF ARIZONA \\ UNIVERSITY OF BRITISH COLUMBIA \\ CALIFORNIA INSTITUTE OF TECHNOLOGY \\ UNIVERSITY OF CALIFORNIA \\ MONTANA STATE UNIVERSITY \\ UNIVERSITY OF NEVADA, RENO \\ NEW MEXICO STATE UNIVERSITY \\ OREGON STATE UNIVERSITY
}

\author{
UNIVERSITY OF OREGON \\ UNIVERSITY OF SOUTHERN CALIFORNIA \\ STANFORD UNIVERSITY \\ UNIVERSITY OF HAWAII \\ UNIVERSITY OF TOKYO \\ UNIVERSITY OF UTAH \\ WASHINGTON STATE UNIVERSITY \\ UNIVERSITY OF WASHINGTON
}

The Supporting Institutions listed above contribute to the cost of publication of this Journal, but they are not owners or publishers and have no responsibility for its content or policies.

Mathematical papers intended for publication in the Pacific Journal of Mathematics should be in typed form or offset-reproduced, (not dittoed), double spaced with large margins. Please do not use built up fractions in the text of the manuscript. However, you may use them in the displayed equations. Underline Greek letters in red, German in green, and script in blue. The first paragraph or two must be capable of being used separately as a synopsis of the entire paper. Please propose a heading for the odd numbered pages of less than 35 characters. Manuscripts, in triplicate, may be sent to any one of the editors. Please classify according to the scheme of Math. Reviews, Index to Vol. 39. Supply name and address of author to whom proofs should be sent. All other communications should be addressed to the managing editor, or Elaine Barth, University of California, Los Angeles, California, 90024.

50 reprints to each author are provided free for each article, only if page charges have been substantially paid. Additional copies may be obtained at cost in multiples of 50 .

The Pacific Journal of Mathematics is issued monthly as of January 1966. Regular subscription rate: $\$ 102.00$ a year (6 Vols., 12 issues). Special rate: $\$ 51.00$ a year to individual members of supporting institutions.

Subscriptions, orders for numbers issued in the last three calendar years, and changes of address shoud be sent to Pacific Journal of Mathematics, P.O. Box 969, Carmel Valley, CA 93924, U.S.A. Old back numbers obtainable from Kraus Periodicals Co., Route 100, Millwood, NY 10546.

PUBLISHED BY PACIFIC JOURNAL OF MATHEMATICS, A NON-PROFIT CORPORATION

Printed at Kokusai Bunken Insatsusha (International Academic Printing Co., Ltd.). 8-8, 3-chome, Takadanobaba, Shinjuku-ku, Tokyo 160, Japan. 


\section{Pacific Journal of Mathematics}

\section{Vol. 98, No. 2 \\ April, 1982}

Thomas E. Armstrong, Barycentric simplicial subdivision of infinite-dimensional simplexes and octahedra

Hom Nath Bhattarai and James William Fernandez, Joins of double coset

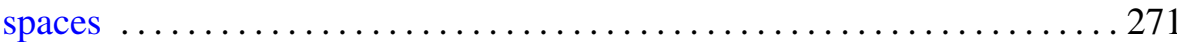

Alexandru Buium, Ritt schemes and torsion theory $\ldots \ldots \ldots \ldots \ldots \ldots \ldots 281$

Jacob Burbea, Operator-valued Pick's conditions and holomorphicity ..... 295

Su-Shing Chen, Duality condition and property $(\mathrm{S}) \ldots \ldots \ldots \ldots \ldots \ldots . \ldots . \ldots 313$

Ky Fan, Evenly distributed subsets of $S^{n}$ and a combinatorial application . . 323

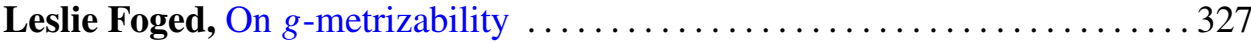

John Groves Heywood, An error estimate uniform in time for spectral

Galerkin approximations of the Navier-Stokes problem ............ 333

Aggie Ho, The Krê̆ n-Milman property and complemented bushes in

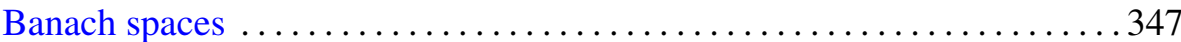

David R. Jackett, Rings on certain mixed abelian groups ............. 365

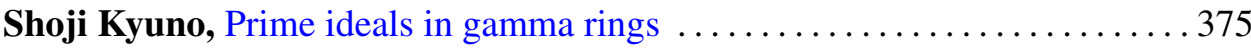

George Lucius O'Brien, Zero-inducing functions on finite abelian

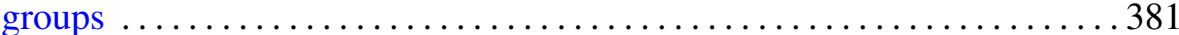

P. Robba, Sur les équations différentielles linéaires $p$-adiques. II ......... 393

Wolfgang Ruess, [Weakly] compact operators and DF spaces ...........419

Claude Schochet, Topological methods for $C^{*}$-algebras. II. Geometry resolutions and the Künneth formula

Harry F. Smith, Jr., Equivalent nilpotencies in certain generalized right

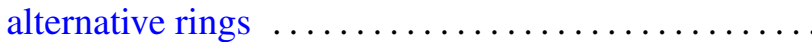

Max Warshauer, Diagonalization up to Witt 469

Hugh C. Williams, A class of primality tests for trinomials which includes the Lucas-Lehmer test 